\title{
Effect of Water Stress on the Growth and Fecundity of Common Waterhemp (Amaranthus rudis)
}

\begin{abstract}
Debalin Sarangi, Suat Irmak, John L. Lindquist, Stevan Z. Knezevic, and Amit J. Jhala*
Common waterhemp is one of the most commonly encountered and troublesome weeds in the midwestern United States. It is well known that water stress adversely affects crop growth and yield; however, the effects of water stress on weed growth and seed production are poorly understood. The objective of this study was to determine the effects of degree and duration of water stress on growth, development, and fecundity of two common waterhemp biotypes in greenhouse experiments conducted at the University of Nebraska-Lincoln. No difference was observed in growth, development, and seed production between two biotypes in response to degree and duration of water stress; therefore, data were combined. The degree of water stress study included five treatments, where the amount of water applied to each pot at 2-d interval was equivalent to 100 , $75,50,25$, and $12.5 \%$ of pot (soil) water content. The highest plant height $(163 \mathrm{~cm})$, number of leaves $\left(231\right.$ plant $\left.^{-1}\right)$, and growth index $\left(4.4 \times 10^{5} \mathrm{~cm}^{3}\right)$ were recorded at $100 \%$ of pot water content (no water stress). Similarly, aboveground biomass, total leaf area, and seed production reached their maximum at $100 \%$ of pot water content treatment, whereas they were reduced as degree of water stress increased. The study of water stress duration included five treatments, where amount of water applied to each pot at 2-, 4-, 6-, 8-, and 10-d intervals was equivalent to $100 \%$ of pot water content. The highest plant height $(150 \mathrm{~cm})$, number of leaves $\left(210\right.$ plant $\left.^{-1}\right)$, and growth index $\left(3.8 \times 10^{5} \mathrm{~cm}^{3}\right)$ were observed at 2-d interval of water stress, whereas seed production was similar at 2-d $\left(36,549\right.$ seeds plant $\left.{ }^{-1}\right)$ and 4 -d $\left(34,176\right.$ seeds plant $\left.^{-1}\right)$ intervals. This study shows that common waterhemp has capacity to survive and reproduce even under a higher degree and duration of water stress.
\end{abstract}

Nomenclature: Common waterhemp; Amaranthus rudis Sauer.

Key words: Aboveground biomass, degree of water stress, duration of water stress, growth index, seed production.

Common waterhemp, a $\mathrm{C}_{4}$ species, is a summer annual broadleaf weed native to North America (Waselkov and Olsen 2014). It is the most problematic and troublesome weed in row-crop production systems throughout the midwestern United States (Hager et al. 2002; Shoup et al. 2003). In Illinois, season-long infestation of common waterhemp reduced corn (Zea mays L.) yield up to $74 \%$ (Steckel and Sprague 2004), and soybean (Glycine max L.) yield was reduced by $43 \%$ when common waterhemp plants were allowed to compete up to $10 \mathrm{wk}$ after soybean unifoliate expansion (Hager et al. 2002). Changes in cultural practices and weed management strategies have helped to increase the crop

\footnotetext{
DOI: $10.1614 /$ WS-D-15-00052.1

${ }^{*}$ First, third, and fifth authors: Graduate Student, Professor, and Assistant Professor, respectively, Department of Agronomy and Horticulture, University of Nebraska-Lincoln, Lincoln, NE 68583; second author: Professor, Department of Biological Systems Engineering, University of Nebraska-Lincoln, Lincoln, NE 68583; fourth author: Professor, Northeast Research and Extension Center, Haskell Agricultural Laboratory, University of Nebraska-Lincoln, Concord, NE 68728. Corresponding author's E-mail: Amit.Jhala@unl.edu
}

productivity in the midwestern United States, but these changes are also believed to aid in the shifting of the weed flora composition and have resulted in the dominance of small-seeded broadleaf weeds, including common waterhemp (Hausman et al. 2011).

Favorable biological attributes and the rapid evolution of herbicide resistance contributed to the dominance of common waterhemp as a successful weed in corn-soybean production systems. Common waterhemp has a rapid growth habit with a high biomass production potential. A study conducted in Kansas revealed that height of common waterhemp increased 0.11 to $0.16 \mathrm{~cm}$ per growing degree day at a relative growth rate of $0.31 \mathrm{~g} \mathrm{~g}^{-1} \mathrm{~d}^{-1}$ (Horak and Loughin 2000). This weed can emerge throughout the growing season, starting from mid-May depending on environmental conditions, making common waterhemp more capable than most weeds of escaping herbicide applications (Hartzler et al. 1999). Moreover, it has the potential to produce over one million seeds per plant under favorable conditions, thus building up a persistent 
seed bank in a relatively short period (Steckel et al. 2003, 2007).

Overreliance on glyphosate as the only method for weed control in glyphosate-resistant crops has created a selective advantage, resulting in the evolution of glyphosate-resistant weeds. Additionally, common waterhemp is a dioecious and wind-pollinated species with a high potential to disseminate herbicideresistant traits via pollen movement (Liu et al. 2012). The first report of glyphosate-resistant common waterhemp in the United States was from Missouri (Legleiter and Bradley 2008), but as of 2015, it has been confirmed in 17 states (Heap 2015), including Nebraska (Sarangi et al. 2015). In addition, common waterhemp biotypes resistant to herbicides with other modes of action, including acetolactate synthase inhibitors, growth regulators, 4-hydroxyphenylpyruvate dioxygenase inhibitors, and photosystem II-inhibitors have been confirmed in Nebraska (Bernards et al. 2012; Jhala 2015). Therefore, use of alternate herbicide-tolerant crops, and application of PRE and a premix of POST herbicides are now becoming more common among the growers to control herbicide-resistant weeds, including common waterhemp in Nebraska (Aulakh and Jhala 2015; Chahal and Jhala 2015; Chahal et al. 2014; Ganie et al. 2015; Kaur et al. 2014).

Weeds compete with commodity crops for a variety of environmental resources, including radiation, nutrients, and water. Among them, water is the most limiting factor for the optimum crop production in the Great Plains and midwestern United States (Benjamin and Nielsen 2006). In early and mid-2000s and recently in 2012, many midwestern states, including Nebraska, experienced a severe drought that had an adverse effect on crop yields and the economy (Wu et al. 2013). Water deficit can adversely affect growth and productivity of the crops and associated weed species, though the outcomes of the competition for water depend on the abilities of the crop and weed species to survive under water stress conditions (Begg and Turner 1976; Patterson 1995). The $\mathrm{C}_{4}$ plants, including common waterhemp, usually have higher water use efficiency and seed production potential that allows them to grow successfully in a wide range of climatic conditions (Long 1999; Lovelli et al. 2010). For example, common waterhemp can be found in places ranging from the arid regions of Texas to the humid/ subhumid areas of Maine (Costea et al. 2005; Nordby et al. 2007).

Environmental stresses such as water deficiency prevent plants from achieving the maximum growth potential set by their genotypes (Patterson 1995). The differences in responses to water stress for different plant species are due to their diverse phenological and physiological processes, and response also depends upon climatic conditions, soil, degree and duration of water stress, and management practices (Irmak et al. 2000). Significant reductions in growth and seed production in some weed species, including Benghal dayflower (Commelina benghalensis L.), itchgrass [Rottboellia cochinchinensis (Lour.) W. D. Clayton], and junglerice [Echinochloa colona (L.) Link] have been reported under different degrees and durations of water stress (Chauhan 2013; Chauhan and Johnson 2010; Webster and Grey 2008). However, availability of limited scientific literature about the water use efficiency of Amaranthus species (Liu and Stützel 2002a; 2002b) was the basis of this study. The objective of this study was to determine the effect of degree and duration of water stress on the growth and fecundity of common waterhemp.

\section{Materials and Methods}

Plant Materials. Seedheads of two different common waterhemp plants were collected from two soybean fields located at Clay County, and Lancaster County, NE, and placed separately in two paper bags. Seeds were cleaned thoroughly using a seed blower (South Dakota Seed Blower, Seedburo Equipment Co., 1022 W. Jackson Blvd., Chicago, IL) and germinated using the procedure described by Sarangi et al. (2015). Seedlings were transplanted to 72-celled germination trays containing potting mix (Berger BM1 All-Purpose Mix, Berger Peat Moss Ltd., Saint-Modeste, Quebec, Canada) allowing one common waterhemp seedling per cell. When seedlings reached $8 \mathrm{~cm}$ in height, they were then transplanted into round, free-draining black plastic pots $(20-\mathrm{cm}$ diam and $30-\mathrm{cm} \mathrm{ht})$ containing finely ground soil. Plants were kept in a greenhouse maintained at a 28/24 C day/night temperature and supplied with adequate water and 24-8-16 commercial plant fertilizer (Miracle-Gro Water Soluble All Purpose Plant Food, Scotts Miracle-Gro Products Inc., 14111 Scottslawn Road, Marysville, OH 43041) until the experiment commenced. Metal halide lamps with $600 \mu \mathrm{mol}$ photon $\mathrm{m}^{-2} \mathrm{~s}^{-1}$ light intensity provided supplemental light in greenhouse to ensure a $16-\mathrm{h}$ photoperiod.

Pot (Soil) Water Content. Soil used in this study was collected from a field near Lincoln, NE, with no history of residual herbicides applied at least in 
the last 5 yr. Air-dried soil was passed through 3-mm sieve to acquire a uniform consistency. The soil texture was silt-loam with a $\mathrm{pH}$ of $6.1,22 \%$ sand, $54 \%$ silt, $24 \%$ clay, $2.8 \%$ organic matter, and bulk density of $1.4 \mathrm{~g} \mathrm{~cm}^{-3}$. Each pot was filled with $10 \mathrm{~kg}$ of dry soil and pot (soil) water content was determined by modifying the method described by Steadman et al. (2004). First, the weight of the pots containing dry soil was measured, then the pots were watered to saturation and covered with shiny paper sheets to minimize the evaporation. They were allowed to freely drain for $36 \mathrm{~h}$, and reweighed to calculate the pot water content using the following equation:

$$
W C=\left[\left(W_{w}-W_{d}\right) / d\right]
$$

where $W_{w}$ is the wet weight of the soil plus pot, $W_{d}$ is the dry weight of the soil plus pot, and $d$ is the density of water (i.e., $1 \mathrm{~g} \mathrm{~cm}^{-3}$ ).

Experimental Setup. A preliminary study was conducted in the greenhouse under the same growing conditions as described above to determine an effective interval for adding water to the common waterhemp plants. The study included five treatments at $1-, 2-, 3-, 4-$, and 5-d intervals of water stress in a randomized complete block design with six replications. In each treatment, water was applied at $100 \%$ of pot water content. Plant height, leaves plant $^{-1}$, and aboveground biomass were measured $45 \mathrm{~d}$ after transplanting (DAT). Results showed that plants treated with $100 \%$ of pot water content at the 2-d interval resulted in the highest plant height, leaves plant ${ }^{-1}$, and aboveground biomass compared to other water stress intervals (data not shown); therefore, a 2-d interval was selected as no water stress treatment for degree and duration of water stress study.

Two separate experiments were conducted for both common waterhemp biotypes in the greenhouse at the University of Nebraska-Lincoln. The treatments were selected based on findings of the preliminary study and by modifying the treatments from available literature on water stress (Chauhan 2013; Chauhan and Johnson 2010, Webster and Grey 2008). For this study, water stress treatments were initiated at 10 DAT and continued until plant harvest at 90 DAT.

Degree of Water Stress. Degree of water stress experiment included five water stress treatments, where the amount of water applied to each pot at 2-d interval was equivalent to $100,75,50,25$, and $12.5 \%$ of pot water content, simulating different degrees of water stress: no, light, moderate, high, and severe water stress, respectively.

Duration of Water Stress. Duration of water stress experiment included treatments of different durations of water stress at 2-, 4-, 6-, 8-, and 10-d intervals. In each treatment, amount of water applied was equivalent to $100 \%$ of pot water content.

Pots from both experiments (degree and duration of water stress) were arranged in a randomized complete block design with six replications and experiments were repeated under similar greenhouse environments.

Data Collection. In both experiments, plant height, leaves plant ${ }^{-1}$, and growth index were determined at $10-\mathrm{d}$ intervals until common waterhemp reached maturity. Growth index is the quantitative indicator for plant growth rate, and was calculated using the following equation (Dhir and Harkess 2011; Irmak et al. 2004):

$$
G I\left(\mathrm{~cm}^{3}\right)=\pi \times(w / 2)^{2} \times h
$$

where $w$ is the width of the plant calculated as an average of two widths, one measured at the widest point and another at $90^{\circ}$ to the first; and $h$ is the plant height measured from soil surface to the last stem-node at the top.

All the leaves from each individual plant were separated from the stem and total leaf area was measured at maturity (90 DAT) using a leaf area meter (LI-3100C Area Meter, LI-COR.Inc. Lincoln, NE). Moreover, aboveground biomass (shoots and leaves) of each common waterhemp plant was bagged separately at maturity (90 DAT) and the roots were washed under a gentle flow of water to remove soil particles. Plant parts were oven-dried at $65 \mathrm{C}$ for $7 \mathrm{~d}$. Aboveground biomass, root biomass, and root: shoot ratio were recorded based on the dry weight of the plant parts. Seeds collected from female common waterhemp plants were threshed and cleaned in the greenhouse using the method described by Steckel et al. (2003). The average weight of five samples of 200 seeds from each plant was recorded and total number of seeds plant ${ }^{-1}$ was calculated. Additionally, germination percentage of common waterhemp seeds obtained from this study was calculated by modifying the method described by Gallagher and Cardina (1998) and Steckel et al. (2003). Two hundred seeds from each 
female plant were placed on a piece of moist Whatman No. 4 filter paper (GE Healthcare UK Limited, Amersham Place Little Chalfont, Buckinghamshire, HP7 9NA, U.K.). Petri dishes were kept in the greenhouse with lids closed to prevent microbial contamination and to minimize the water loss through evaporation. The cumulative germination of common waterhemp seeds were counted at $15-\mathrm{d}$ interval up to $45 \mathrm{~d}$ after starting the germination study. The percentage of germination was calculated based on seeds germinated vs. number of seeds planted.

Statistical Analysis. Data were subjected to ANOVA using the PROC GLIMMIX procedure in SAS (SAS Institute Inc, Cary, NC). Years (experimental runs) and blocks (nested within year) were considered random effects, whereas biotypes (from Clay County and Lancaster County, NE) and water stress treatments were considered fixed effects in the model. A four-parameter log-logistic sigmoid growth function (Equation 3) was regressed on plant height, leaves plant ${ }^{-1}$, and growth index using software $R(R$ statistical software, R Foundation for Statistical Computing, Vienna, Austria) (Knezevic et al. 2007):

$$
Y=c+\{d-c / 1+\exp [b(\log x-\log e)]\} .
$$

In this model, $Y$ is plant height, leaves plant $^{-1}$, or growth index at time $x$ (DAT); $c$ is the lower limit considered as 0 ; $d$ is the estimated maximum plant height or leaf number or growth index; and $e$ is the time taken to reach $50 \%$ of final height, leaf number, or growth index. The parameter $b$ is relative slope around parameter $e$. For the data of total leaf area, biomass, root: shoot ratio, seed production, and percentage of germination, treatment means were separated at $\mathrm{P} \leq 0.05$ using Fisher's protected LSD test and plots were generated by using SigmaPlot (SigmaPlot 12.0, Systat Software Inc., San Jose, CA).

Model Goodness of Fit. Root mean square error (RMSE) and modelling efficiency coefficient (EF) were calculated to test the goodness of fit for the model. They are the commonly used to estimate model quality (Werle et al. 2014b; 2014c). The RMSE was calculated based on an equation (Roman et al. 2000):

$$
R M S E=\left[\frac{1}{n} \sum_{i=1}^{n}\left(P_{i}-O_{i}\right)^{2}\right]^{1 / 2}
$$

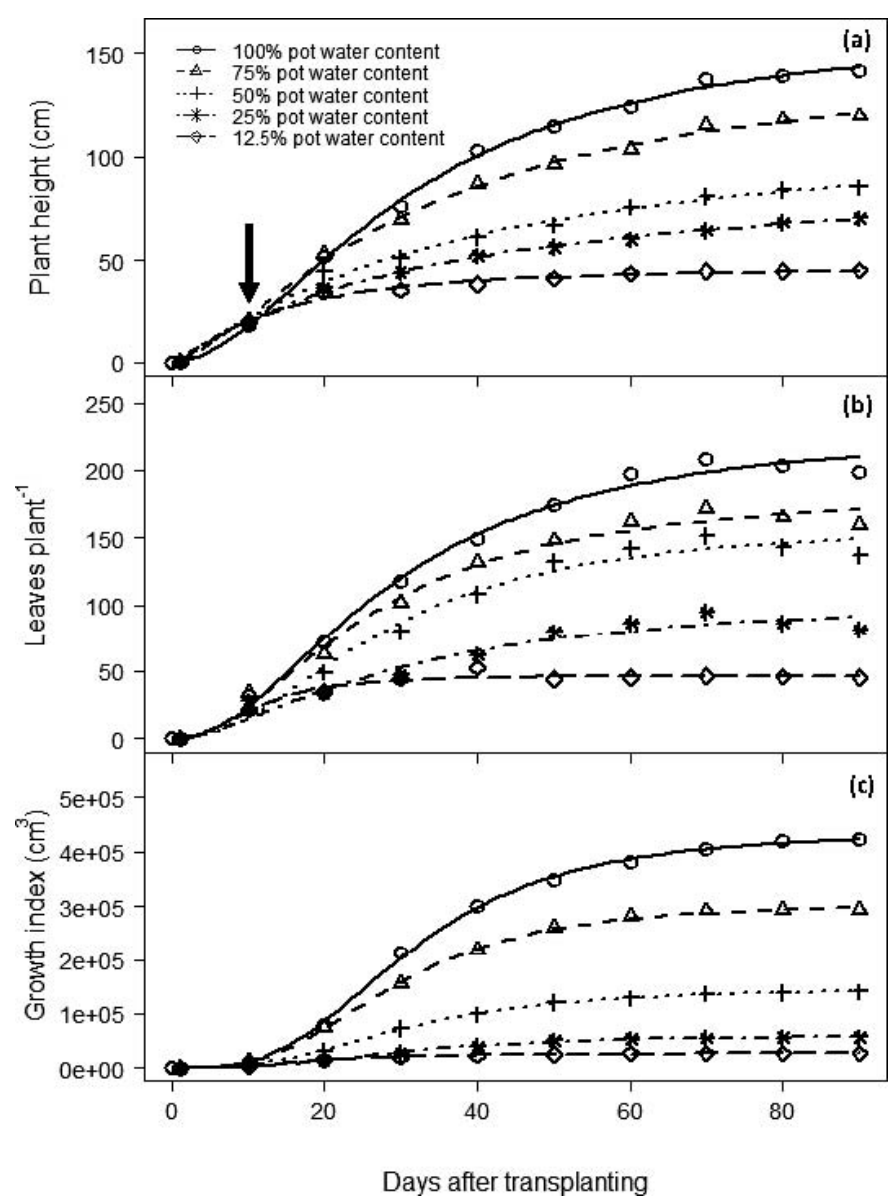

Figure 1. Effect of degree of water stress on (a) height, (b) leaves plant $^{-1}$, and (c) growth index of common waterhemp in a greenhouse study conducted in Nebraska, where 100, 75, 50, 25, and $12.5 \%$ pot water content treatments were considered as no, light, moderate, high, and severe water stress, respectively. The arrow at $10 \mathrm{~d}$ after transplanting (DAT) denotes the first day when water stress treatments were imposed.

where $P_{i}$ is the predicted value, $O_{i}$ is the observed value, and $n$ is the total number of observations. Smaller RMSE value means better fit to the model due to closer observed and predicted values. The evaluation of $R^{2}$ is an inadequate measure for nonlinear models such as Equation 3, as it is extremely biased to highly parametrized models (Spiess and Neumeyer 2010); therefore EF, which is different from $R^{2}$ by having a lower bound, was calculated (Mayer and Butler 1993):

$$
E F=1-\left[\sum_{i=1}^{n}\left(O_{i}-P_{i}\right)^{2} / \sum_{i=1}^{n}\left(O_{i}-\bar{O}_{i}\right)^{2}\right]
$$

where $O_{i}$ is the observed value, and $P_{i}$ is the predicted value, $\bar{O}_{i}$ is the mean observed value, and $n$ is the total number of observations. Generally, 
Table 1. Parameter estimates and the goodness of fit (RMSE, and EF) ${ }^{\mathrm{a}}$ of the four-parameter log-logistic function ${ }^{\mathrm{b}}$ fitted to common waterhemp plant height, leaves plant ${ }^{-1}$, and growth index under different degree of water stress treatments in a greenhouse experiment conducted in Nebraska.

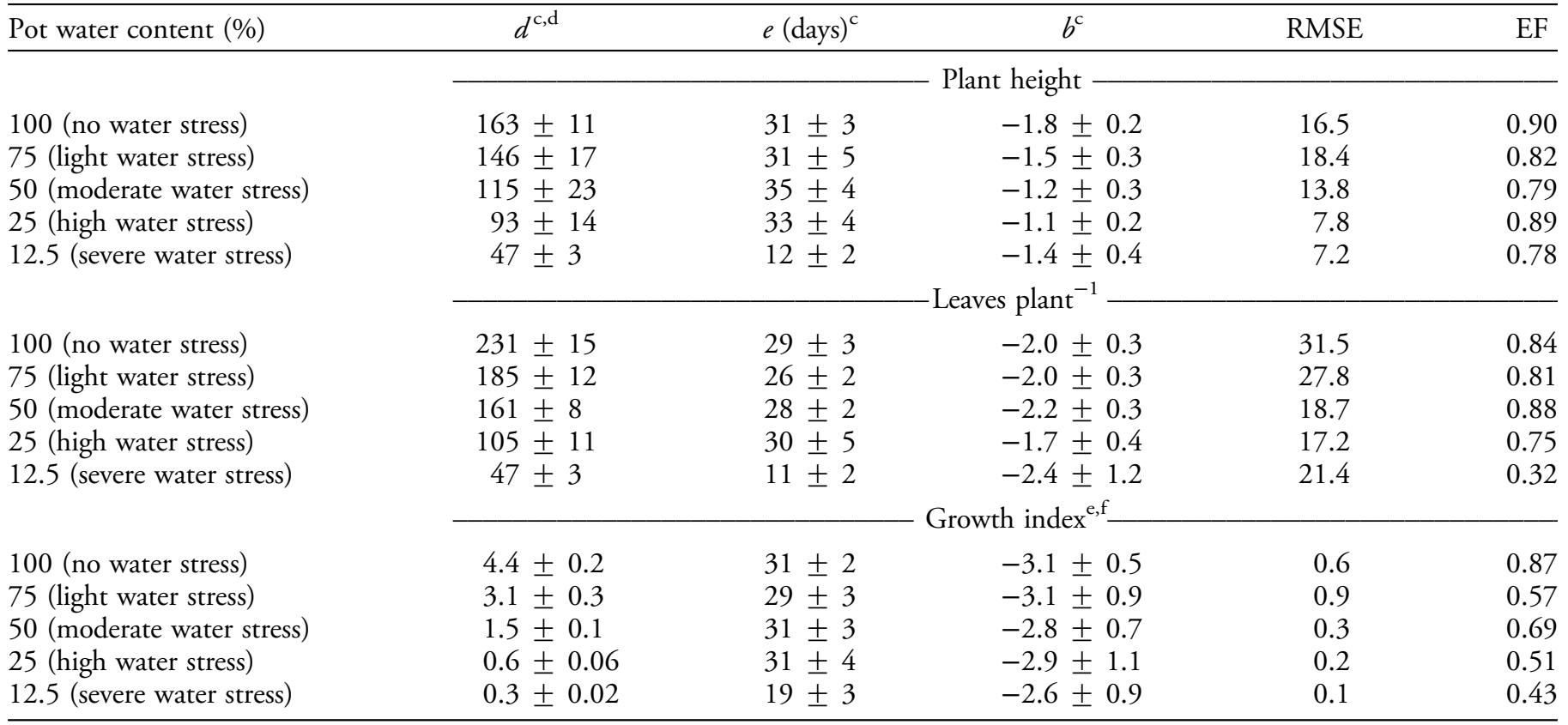

${ }^{a}$ Abbreviations: RMSE, root mean square error; EF, modelling efficiency coefficient.

${ }^{\mathrm{b}} Y=c+\{d-c / 1+\exp [b(\log x-\log e)]\}$, where $Y$ is the plant height, leaves plant ${ }^{-1}$, or growth index at time $x$ (days after transplanting); $c$ is the lower limit considered as $0 ; d$ is the estimated maximum plant height or leaf number or growth index; $e$ is the time taken to reach $50 \%$ of final height, leaf number, or growth index; and $b$ is the relative slope around the parameter $e$.

${ }^{\mathrm{c}}$ Values are mean \pm SEM.

${ }^{\mathrm{d}}$ The unit of the parameter $d$ is $\mathrm{cm}$, no. plant ${ }^{-1}, \mathrm{~cm}^{3}$ for the plant height, leaves plant ${ }^{-1}$, and growth index, respectively.

${ }^{\mathrm{e}}$ Growth index $=\pi \times(w / 2)^{2} \times h$, where $w$ is the width of the plant and $h$ is the plant height.

${ }^{\mathrm{f}}$ Values presented for $d$ and RMSE are divided by $10^{5}$.

EF value ranges between $-\infty$ and 1 ; values closer to 1 means more accurate predictions.

\section{Results and Discussion}

Common waterhemp biotypes from two Nebraska counties responded similarly $(\mathrm{P}>0.05)$ to degree and duration of water stress. Treatment-byexperiment interaction was not significant in either study; therefore, data from both biotypes and years were combined.

Degree of Water Stress. Degree of water stress influenced growth and fecundity of common waterhemp. With reduced degrees of water stress, common waterhemp plant height, leaves plant $^{-1}$, and growth index increased following a log-logistic sigmoid growth function (Figure 1). Maximum plant height $(d)$ estimated by the model was $163 \mathrm{~cm}$ when amount of water was equivalent to $100 \%$ of pot water content (no water stress), which was reduced to 146 and $115 \mathrm{~cm}$ with 75\% (light water stress) and 50\% (moderate water stress) of pot water content, respectively (Table 1). Compared with
$100 \%$ of pot water content (no water stress), estimated maximum plant height was reduced by 43 and $71 \%$ when amount of water added to the plants were $25 \%$ (high water stress) and $12.5 \%$ (severe water stress) of pot water content, respectively. Chauhan (2013) reported that plant height of itchgrass, another $\mathrm{C}_{4}$ weed species, was reduced by 49 and $63 \%$ at 25 and $12.5 \%$ of pot water content, respectively. Common waterhemp plants took $31 \mathrm{~d}$ (e) to reach $50 \%$ of the estimated maximum plant height with the treatments of $100 \%$ (no water stress) and $75 \%$ (light water stress) of pot water content as compared with $12 \mathrm{~d}$ for $12.5 \%$ of pot water content (severe water stress) (Table 1). This is because the plants under severe water stress did not survive 30 DAT, resulting in a flat curve for plant height (Figure 1a).

The highest number of leaves (231 leaves plant ${ }^{-1}$ ) was recorded with $100 \%$ of pot water content treatment (no water stress), whereas increasing level of water stress decreased the number of leaves plant ${ }^{-1}$ (Figure $1 \mathrm{~b}$ ). Compared to $100 \%$ of pot water content (no water stress), estimated maximum number of leaves plant ${ }^{-1}$ were reduced by $>30 \%$ when 

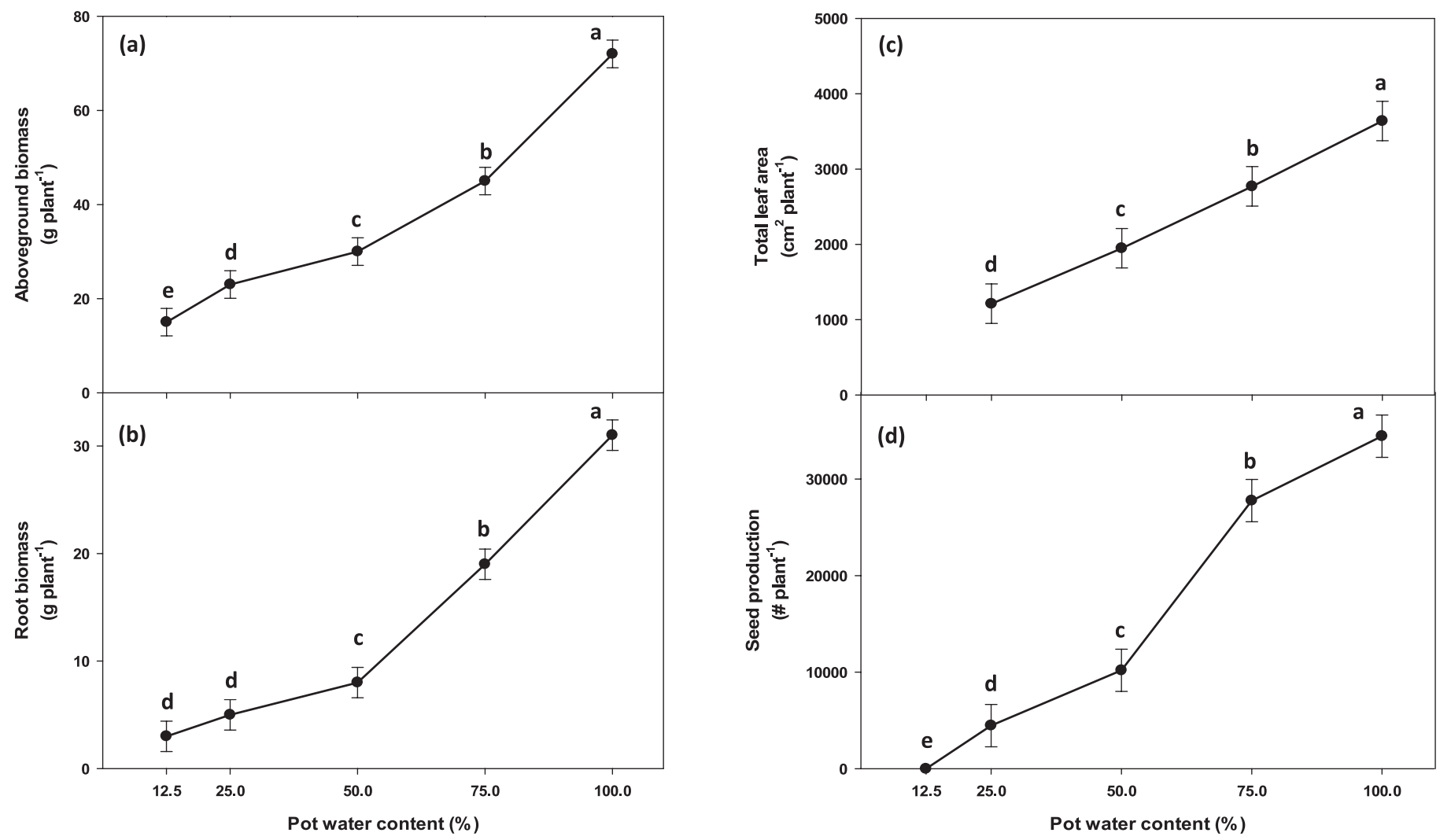

Figure 2. Effect of degree of water stress on (a) aboveground biomass, (b) root biomass, (c) total leaf area, and (d) seed production of common waterhemp in a greenhouse study conducted in Nebraska.

applied water was equivalent to $\leq 50 \%$ of pot water content (moderate to severe water stress) (Table 1). Maximum numbers of leaves estimated by the model were 105 and 47 leaves plant ${ }^{-1}$ with 25\% (high water stress) and $12.5 \%$ (severe water stress) of pot water content, respectively. The model estimated that $50 \%$ of maximum leaves were reached within 26 to $30 \mathrm{~d}$ at 25 to $100 \%$ of pot water content (high to no water stress) (Table 1).

Growth index is the cumulative effect of plant width and plant height (Equation 2). Therefore, the growth index followed a similar pattern as plant height under water stress conditions. Model-estimated highest growth index $\left(4.4 \times 10^{5} \mathrm{~cm}^{3}\right.$ plant $^{-1}$ ) was observed with the $100 \%$ of pot water content (no water stress) treatment, whereas comparatively lower growth index $\left(\leq 3.1 \times 10^{5} \mathrm{~cm}^{3}\right.$ plant $^{-1}$ ) was observed when water was added at $75 \%$ of pot water content (light water stress) or less (Figure 1c; Table 1). Compared to the treatment of $100 \%$ of pot water content, growth index was reduced by $30,66,86$, and $93 \%$ when amount of applied water was equivalent to $75 \%$ (light water stress), 50\% (moderate water stress), 25\% (high water stress), and $12.5 \%$ (severe water stress) of pot water content. Based on the estimation, $50 \%$ of maximum growth index was achieved at $\geqslant 29$
DAT under 25 to $100 \%$ of pot water content (high to no water stress) treatments compared to only $19 \mathrm{~d}$ under $12.5 \%$ of pot water content (severe water stress) (Table 1).

The RMSE values for plant height and number of leaves plant $^{-1}$ ranged from 7.2 to 31.5 (Table 1), indicating a good fit of the model. Roman et al. (2000) reported an RMSE value of 6.5 to 37.1 during validation of a model to predict emergence of common lambsquarters (Chenopodium album L.). Most of the EF values for plant height and leaves plant $^{-1}$ ranged from 0.75 to 0.90 (Table 1 ); indicating the good fit of the model. The EF value for leaves plant $^{-1}$ under $12.5 \%$ of pot water content (severe water stress) was lower (0.32) compared to other treatments because of more variation in the data set and flat curves after 30 DAT. The RMSE values for growth index were higher, ranging from $0.1 \times$ $10^{5}$ to $0.9 \times 10^{5}$ (Table 1$)$. Growth index is an interaction between plant height and plant width and it may lead to the higher values and variations for the observed data set. However EF values, ranging from 0.43 to 0.87 , showed the goodness of fit for the predicted model.

The highest aboveground biomass (72 $\mathrm{g}$ plant $^{-1}$ ) and root biomass $\left(31 \mathrm{~g} \mathrm{plant}^{-1}\right.$ ) were recorded in plants receiving $100 \%$ of pot water content (no 
water stress); whereas biomass production was reduced with increasing degrees of water stress (Figures 2a and 2b), similar to responses reported for itchgrass and junglerice (Chauhan 2013, Chauhan and Johnson 2010). Compared with 100\% of pot water content (no water stress), the aboveground biomass was reduced by 68 and $79 \%$ with $25 \%$ (high water stress) and $12.5 \%$ (severe water stress) of pot water content, respectively. A higher root: shoot ratio $(\geqslant 0.42)$ was observed with the treatments of 100\% (no water stress) and 75\% (light water stress) of pot water content, whereas the root: shoot ratio was the lowest $(\leq 0.22)$ with high $(25 \%$ of pot water content) to severe $(12.5 \%$ of pot water content) water stress (data not shown). Similarly, Moore and Franklin (2011) reported that root: shoot ratio of Palmer amaranth (Amaranthus palmeri S. Wats.), a closely related species of common waterhemp, was reduced under water stress compared with drained and flooded conditions. Total leaf area is dependent on plant growth and the total number of leaves plant ${ }^{-1}$. At 90 DAT, common waterhemp plants produced the highest leaf area $\left(3,638 \mathrm{~cm}^{2}\right.$ plant $\left.^{-1}\right)$ with $100 \%$ of pot water content (no water stress) treatment, whereas total leaf area decreased with increasing water stress (Figure 2c). Compared to the $100 \%$ of pot water content (no water stress) treatment, total leaf area was reduced by 46 and $67 \%$ at $50 \%$ (moderate water stress) and $25 \%$ (severe water stress) of pot water content, respectively. Plants under severe water stress treatment did not survive after 30 DAT.

Seed production declined with increasing degree of water stress (Figure $2 \mathrm{~d}$ ). The highest number of seeds $\left(34,450\right.$ seeds plant $\left.^{-1}\right)$ was produced with $100 \%$ of pot water content (no water stress) as compared with 27,775 seeds plant ${ }^{-1}$ at $75 \%$ of pot water content (light water stress). Surprisingly, plants receiving moderate and high water stress were able to produce 10,194 and 4,469 seeds plant ${ }^{-1}$, respectively. Reduction in seed production has been reported with increased water stress in itchgrass and junglerice (Chauhan 2013, Chauhan and Johnson 2010). As expected, no seeds were produced by the plants under severe water stress, since these plants did not survive more than 30 DAT.

Duration of Water Stress. Duration of water stress had a significant effect on growth and fecundity of common waterhemp. Similar to the degree of water stress study, a sigmoidal log-logistic response was observed for common waterhemp plant height, leaves plant $^{-1}$, and growth index under different

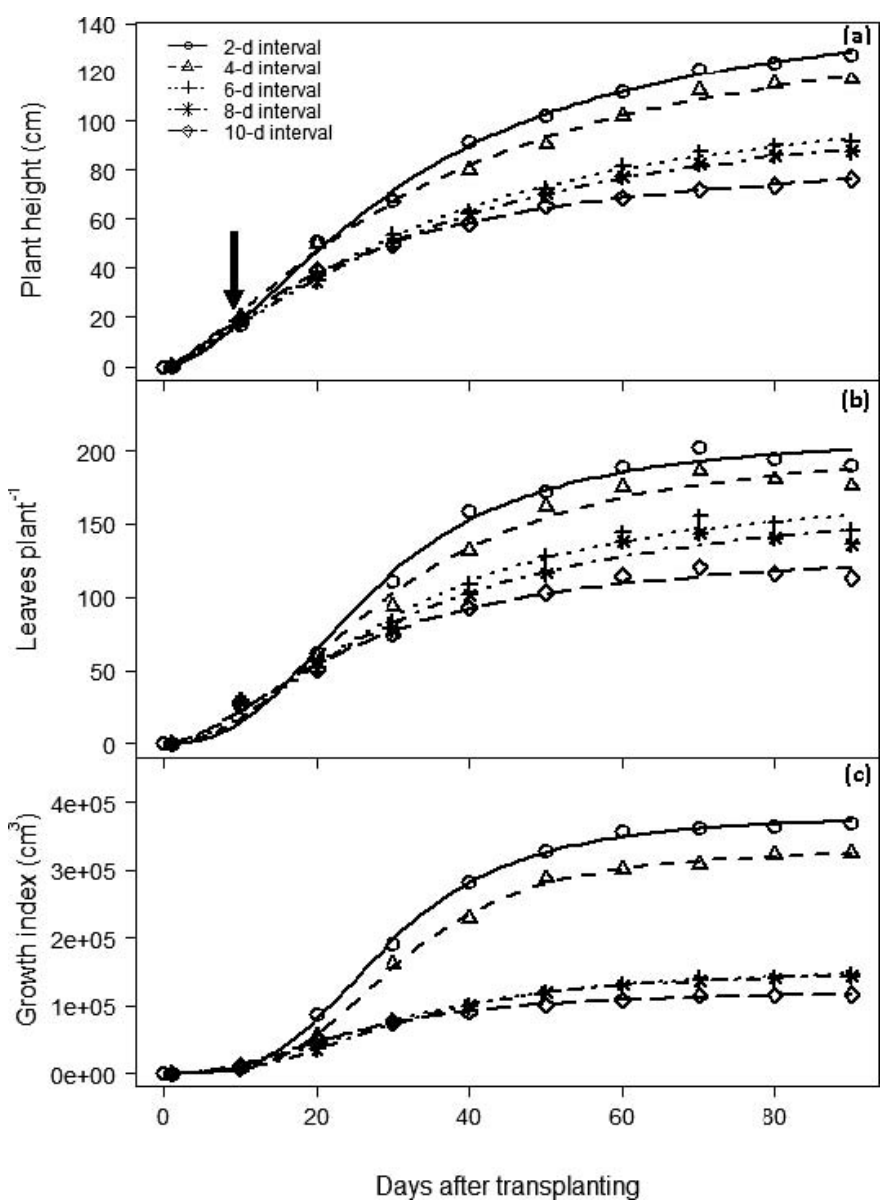

Figure 3. Effect of duration of water stress on (a) height, (b) leaves plant ${ }^{-1}$, and (c) growth index of common waterhemp in a greenhouse study conducted in Nebraska. The arrow at $10 \mathrm{~d}$ after transplanting (DAT) denotes the first day when water stress treatments were imposed.

intervals of water stress (Figure 3). The estimated maximum plant height (d) from the model was similar $(150 \mathrm{~cm})$ for 2 - and 4-d intervals of water stress, whereas it was reduced to $118 \mathrm{~cm}$ for the $6-\mathrm{d}$ water stress interval (Table 2). Similar responses were observed by Chauhan (2013) in itchgrass, where 1and 3-d intervals of water stress resulted in similar estimated maximum plant height, and increasing duration of water stress decreased plant height. Compared to the 2-d water stress interval, maximum plant height was reduced by 25 and $41 \%$ at 8 - and $10-\mathrm{d}$ intervals of water stress, respectively. Based on the estimation, common waterhemp plants required $32 \mathrm{~d}(e)$ to reach $50 \%$ of the maximum plant height at a 2-d water stress interval and with 4-, 6-, and 8-d intervals, they required $35 \mathrm{~d}$ (Figure $3 \mathrm{a}$ ). The number of leaves was highest (210 leaves plant $\left.{ }^{-1}\right)$ at the 2-d interval of water stress, whereas at 4- and 6-d intervals, plants produced 204 and 174 leaves plant $^{-1}$, respectively (Table 2 ). In contrast with the 2-d water stress interval, estimated maximum leaves 
Table 2. Parameter estimates and the goodness of fit (RMSE, and EF) ${ }^{\mathrm{a}}$ of the four-parameter log-logistic function ${ }^{\mathrm{b}}$ fitted to common waterhemp plant height, leaves plant ${ }^{-1}$, and growth index under different duration of water stress treatments in a greenhouse experiment conducted in Nebraska.

\begin{tabular}{|c|c|c|c|c|c|}
\hline Duration of water stress & $d^{\mathrm{c}, \mathrm{d}}$ & 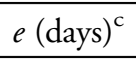 & $b^{\mathrm{c}}$ & RMSE & $\mathrm{EF}$ \\
\hline 2-d interval & $150 \pm 9$ & $32 \pm 3$ & $-1.7 \pm 0.2$ & 11.6 & 0.93 \\
\hline 6-d interval & $118 \pm 10$ & $35 \pm 5$ & $-1.4 \pm 0.2$ & 7.9 & 0.94 \\
\hline 8-d interval & $113 \pm 7$ & $35 \pm 3$ & $-1.4 \pm 0.1$ & 5.4 & 0.97 \\
\hline 10-d interval & $88 \pm 9$ & $24 \pm 4$ & $-1.4 \pm 0.3$ & 10.9 & 0.83 \\
\hline 2-d interval & $210 \pm 9$ & $27 \pm 1$ & $-2.6 \pm 0.4$ & 27.3 & 0.87 \\
\hline 4-d interval & $204 \pm 10$ & $30 \pm 2$ & $-2.2 \pm 0.3$ & 23.1 & 0.89 \\
\hline 6-d interval & $174 \pm 14$ & $30 \pm 3$ & $-1.9 \pm 0.3$ & 25.3 & 0.81 \\
\hline 8-d interval & $170 \pm 19$ & $31 \pm 5$ & $-1.7 \pm 0.4$ & 26.9 & 0.77 \\
\hline 10-d interval & $133 \pm 9$ & $25 \pm 3$ & $-1.7 \pm 0.3$ & 17.1 & 0.84 \\
\hline 8-d interval & $1.5 \pm 0.1$ & $31 \pm 4$ & $-2.7 \pm 0.8$ & 0.4 & 0.64 \\
\hline $10-\mathrm{d}$ interval & $1.2 \pm 0.1$ & $24 \pm 4$ & $-2.3 \pm 0.7$ & 0.4 & 0.56 \\
\hline
\end{tabular}

${ }^{\text {a }}$ Abbreviations: RMSE, root mean square error; EF, modelling efficiency coefficient.

${ }^{\mathrm{b}} Y=c+\{d-c / 1+\exp [b(\log x-\log e)]\}$, where $Y$ is the plant height, leaves plant ${ }^{-1}$, or growth index at time $x$ (days after transplanting); $c$ is the lower limit considered as 0 ; $d$ is the estimated maximum plant height or leaf number or growth index, $e$ is the time taken to reach $50 \%$ of final height, leaf number, or growth index; and $b$ is the relative slope around the parameter $e$.

${ }^{c}$ Values are mean \pm SEM.

$\mathrm{d}$ The unit of the parameter $d$ is $\mathrm{cm}$, no. plant ${ }^{-1}, \mathrm{~cm}^{3}$ for the plant height, leaves plant ${ }^{-1}$, and growth index, respectively.

${ }^{\mathrm{e}}$ Growth index $=\pi \times(w / 2)^{2} \times h$, where $w$ is the width of the plant and $h$ is the plant height.

${ }^{\mathrm{f}}$ Values presented for $d$ and RMSE are divided by $10^{5}$.

plant $^{-1}$ were reduced by 19 and $37 \%$ at 8 - and $10-\mathrm{d}$ intervals of water stress (Figure $3 \mathrm{~b}$ ). The highest growth index $\left(3.8 \times 10^{5} \mathrm{~cm}^{3}\right.$ plant $\left.^{-1}\right)$ was observed at 2-d interval of water stress compared to other treatments, requiring $29 \mathrm{~d}$ to reach the $50 \%$ of the estimated maximum growth index (Figure $3 c)$. Compared to the 2-d interval of water stress, growth index was reduced by $13,58,61$, and $68 \%$ at 4-, 6-, 8-, and 10-d intervals, respectively.

The RMSE and EF values for the plant height and leaves plant ${ }^{-1}$ ranged from 5.4 to 27.3 , and 0.77 to 0.97 (Table 2), respectively; indicating the good fit of the model. Werle et al. (2014a) predicted the emergence of winter annual weeds and reported the RMSE and EF ranging from 13.4 to 23.1 and 0.63 to 0.85 , respectively. The RMSE values for growth index were higher, ranging from $0.2 \times 10^{5}$ to $0.9 \times 10^{5}$ (Table 2), whereas EF values ranged from 0.56 to 0.86 . The higher RMSE values for growth index could be due to the higher numbers and more variations among the observed data set.

The aboveground and root biomass decreased with increasing duration of water stress (Figures 4a and 4b). Similarly, Chauhan (2013) reported reduction in itchgrass biomass with increasing durations of water stress. The highest aboveground biomass (59 $\mathrm{g} \mathrm{plant}^{-1}$ ) was recorded at the 2-d interval of water stress, whereas similar trend was observed in the root biomass $\left(30 \mathrm{~g} \mathrm{plant}^{-1}\right)$. Compared to the 2-d interval of water stress, aboveground biomass was reduced by 39 and $51 \%$ at 8 - and $10-d$ intervals, respectively (Figure 4a). Common waterhemp root biomass was sharply reduced with increasing duration of water stress (Figure 4b), but it was similar at 6-and 8-d intervals of water stress. Root: shoot ratio was highest $(0.51)$ at a 2 -d interval of water stress, whereas it was similar (0.39 to 0.44$)$ at 4- to 8-d intervals (data not shown). At 90 DAT, total leaf area was similar at 2-d $\left(3,913 \mathrm{~cm}^{2}\right.$ plant $\left.^{-1}\right)$ and 4-d $\left(3,265 \mathrm{~cm}^{2}\right.$ plant $\left.^{-1}\right)$ intervals of water stress (Figure 4c). Seed production is the most important characteristic of a weed for reproduction and survival, and increasing duration of water stress usually reduces seed production (Chauhan 2013). Common waterhemp seed production was highest $(34,176$ to 36,549 seeds plant ${ }^{-1}$ ) at 2 - and 4-d intervals of water stress (Figure 4d), but was reduced by 42, 51, and 

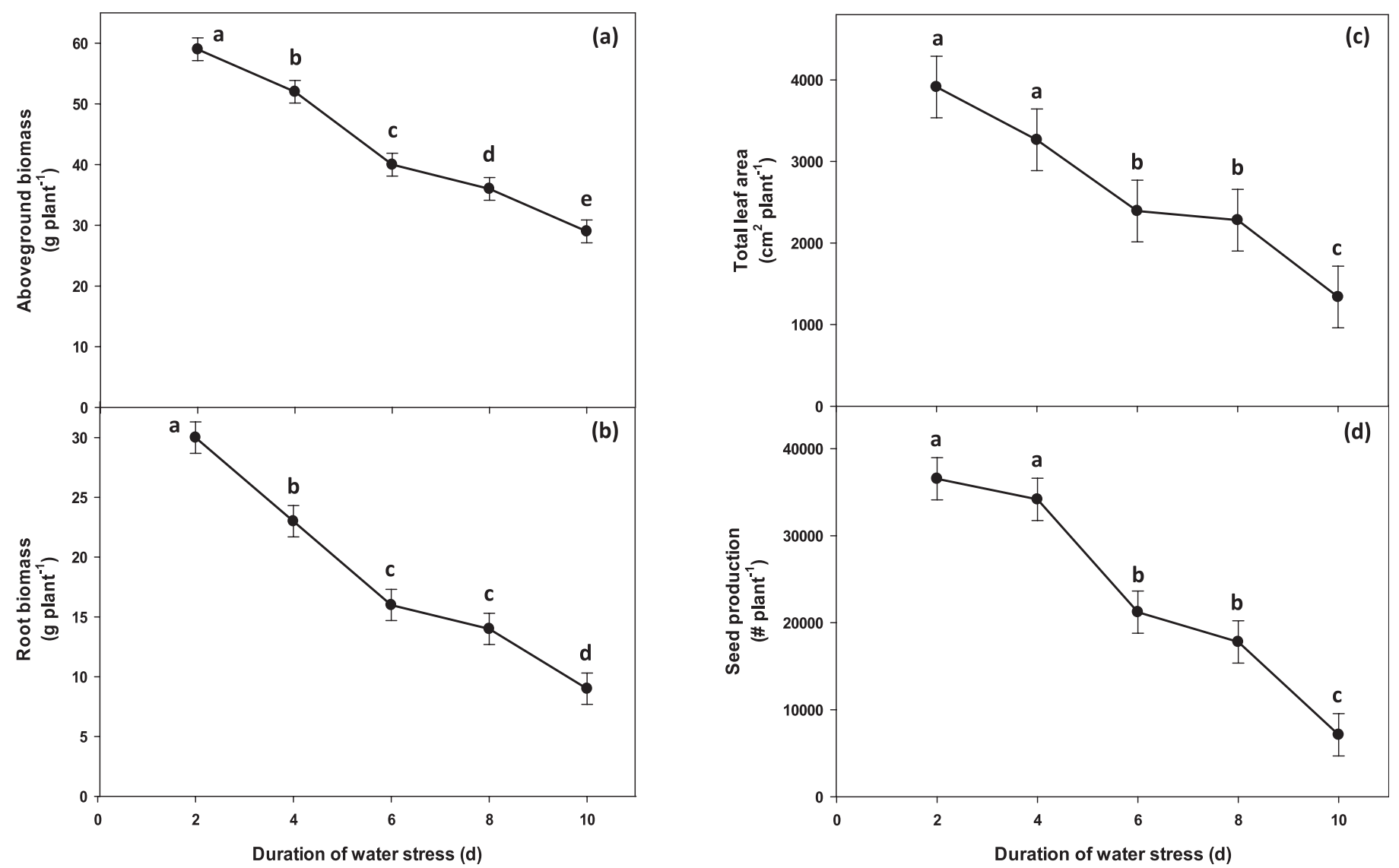

Figure 4. Effect of duration of water stress on (a) aboveground biomass, (b) root biomass, (c) total leaf area, and (d) seed production of common waterhemp in a greenhouse study conducted in Nebraska.

$80 \%$ at 6-, 8-, and 10-d intervals of water stress, respectively.

This study revealed that water stress can impact growth and seed production of common waterhemp. Similarly, Moran and Showler (2005) reported that water stress can reduce shoot height and fresh weight of Palmer amaranth by 31 and 35\%, respectively, when $25 \%$ of pot water content water was added at 4-d interval. Reduction in plant root elongation under water stress conditions was reported by Bengough et al. (2011), mainly due to an increase in mechanical impedance in the dry soil. Moreover, Masle and Passioura (1987) and Young et al. (1997) reported that root and shoot growth are correlated and as a result, leaf expansion can be affected by water deficit, supporting the response of common waterhemp to water stress observed in this study. Seed dormancy of certain species plays a key role in developing an effective weed management strategy. Fenner (1991) reported that water stress during seed development can affect the germination of subsequent seeds depending on a species' mechanism of dormancy. In this study, water stress had no effect on germination of common waterhemp seeds (data not shown). Similarly, Chauhan and Johnson (2010) reported that junglerice seed production was reduced sharply with increasing duration of water stress, but with no effect on seed germination.

Water stress may influence the critical weed-free period for different crop species (Patterson 1995). Weed species that have faster growth rates with high biomass production ability, and preempt the available growth resources, would be considered as a highly competitive weed species over other slowgrowing species (Horak and Loughin 2000). Results of this study will provide information about biological attributes of common waterhemp under water stress conditions that can be used to understand and evaluate the effects of environmental stress on the weed-crop interaction by using a mathematical model in the future. This information can also be used for developing climate simulation models to understand the effect of drought on crop and weed species in the future. Additionally, it is known that efficacy of POST herbicides is reduced under water stress situations due to less retention and uptake of herbicides by the target plants (Kudsk and Kristensen 1992). For example, uptake of glyphosate decreased in black nightshade (Solanum nigrum L.) when plants were under water stress (Ruiter and 
Meinen 1998). Therefore, future research should focus on relative competitiveness of common waterhemp with different crop species and response to POST herbicides under water stress conditions.

\section{Acknowledgments}

The authors thank Indian Council of Agricultural Research, New Delhi, India, for partial financial support to the graduate student involved in this study. We appreciate the help of Bradley Meusch, Ian Rogers, Irvin Schleufer, and Mason Adams in this project.

\section{Literature Cited}

Aulakh JS, Jhala AJ (2015) Comparison of glufosinate-based herbicide programs for broad-spectrum weed control in glufosinate-resistant soybean. Weed Technol 29:419-430

Begg JE, Turner NC (1976) Crop water deficits. Adv Agron 28:161-217

Bengough AG, McKenzie BM, Hallett PD, Valentine TA (2011) Root elongation, water stress, and mechanical impedance: a review of limiting stresses and beneficial root tip traits. J Exp Bot 62:59-68

Benjamin JG, Nielsen DC (2006) Water deficit effects on root distribution of soybean, field pea and chickpea. Field Crops Res 97:248-253

Bernards ML, Crespo RJ, Kruger GR, Gaussoin R, Tranel PJ (2012) A waterhemp (Amaranthus tuberculatus) population resistant to 2,4-D. Weed Sci 60:379-384

Chahal PS, Jhala AJ (2015) Herbicide programs for control of glyphosate-resistant volunteer corn in glufosinate-resistant soybean. Weed Technol 29:431-443

Chahal PS, Kruger G, Blanco H, Jhala AJ (2014) Efficacy of preemergence and post-emergence soybean herbicides for control of glufosinate-, glyphosate-, and imidazolinone-resistant volunteer corn. J Agric Sci 6:131-140

Chauhan BS (2013) Growth response of itchgrass (Rottboellia cochinchinensis) to water stress. Weed Sci 61:98-103

Chauhan BS, Johnson DE (2010) Growth and reproduction of junglerice (Echinochloa colona) in response to water-stress. Weed Sci 58:132-135

Costea M, Weaver SE, Tardif FJ (2005) The biology of invasive alien plants in Canada. 3. Amaranthus tuberculatus (Moq.) Sauer var. rudis (Sauer) Costea \& Tardif. Can J Pl Sci 85:507-522

Dhir R, Harkess RL (2011) Elevated air temperatures cause foliar bleaching of ivy geranium 'Beach' and 'Butterfly'. HortScience 46:411-415

Fenner M (1991) The effects of the parent environment on seed germinability. Seed Sci Res 1:75-84

Gallagher RS, Cardina J (1998) Phytochrome-mediated Amaranthus germination II: development of very low fluence sensitivity. Weed Sci 46:53-58

Ganie ZA, Stratman G, Jhala AJ (2015) Response of selected glyphosate-resistant broadleaved weeds to premix of fluthiacetmethyl and mesotrione (Solstice ${ }^{\mathrm{TM}}$ ) applied at two growth stages. Can J Plant Sci 95: 861-869
Hager AG, Wax LM, Stoller EW, Bollero GA (2002) Common waterhemp (Amaranthus rudis) interference in soybean. Weed Sci 50:607-610

Hartzler RG, Buhler DD, Stoltenberg DE (1999) Emergence characteristics of four annual weed species. Weed Sci 47:578-584

Hausman NE, Singh S, Tranel PJ, Riechers DE, Kaundun SS, Polge ND, Thomas DA, Hager AG (2011) Resistance to HPPD-inhibiting herbicides in a population of waterhemp (Amaranthus tuberculatus) from Illinois, United States. Pest Manag Sci 67:258-261

Heap I (2015) The International Survey of Herbicide Resistant Weeds. Herbicide Resistant Tall Waterhemp Globally. http:// weedscience.org/Summary/Species.aspx? WeedID =219. Accessed May 30, 2015

Horak MJ, Loughin TM (2000) Growth analysis of four Amaranthus species. Weed Sci 48:347-355

Irmak S, Haman DZ, Bastug R (2000) Determination of crop water stress index for irrigation timing and yield estimation of corn. Agron J 92:1221-1227

Irmak S, Haman DZ, Irmak A, Jones JW, Campbell KL, Crisman TL (2004) Measurement and analysis of growth and stress parameters of Viburnum odoratissimum (Ker-gawl) grown in a multi-plot box system. HortScience 39:1445-1455

Jhala AJ (2015) Herbicide-resistant weeds. Pages 18-19 in Knezevic SZ, Jhala AJ, Klein RN, Kruger GR, Reicher ZJ, Wilson RG, Shea PJ, Ogg CL, eds. 2015 Guide for Weed Management in Nebraska with Insecticide and Fungicide Information. Lincoln, NE: University of Nebraska-Lincoln Extension

Kaur S, Sandell LD, Lindquist JL, Jhala AJ (2014) Glyphosateresistant giant ragweed (Ambrosia trifida) control in glufosinate-resistant soybean. Weed Technol 28:569-577

Knezevic SZ, Streibig JC, Ritz C (2007) Utilizing R software package for dose-response studies: the concept and data analysis. Weed Technol 21:840-848

Kudsk P, Kristensen JL (1992) Effect of environmental factors on herbicide performance. Pages 173-186 in Proceedings of the First International Weed Control Congress. Melbourne, Australia: Weed Science Society of Victoria Inc

Legleiter TR, Bradley KW (2008) Glyphosate and multiple herbicide resistance in common waterhemp (Amaranthus rudis) populations from Missouri. Weed Sci 56:582-587

Liu F, Stützel H (2002a) Leaf expansion, stomatal conductance, and transpiration of vegetable amaranth (Amaranthus sp.) in response to soil drying. J Am Soc Hortic Sci 127:878-883

Liu F, Stützel H (2002b) Leaf water relations of vegetable amaranth (Amaranthus spp.) in response to soil drying. Eur J Agron 16:137-150

Liu J, Davis AS, Tranel PJ (2012) Pollen biology and dispersal dynamics in waterhemp (Amaranthus tuberculatus). Weed Sci 60:416-422

Long SP (1999) Ecology of $\mathrm{C}_{4}$ photosynthesis-environmental responses. Pages 215-249 in Sage RF and Monson RK, eds. C4 Plant Biology. San Diego, CA: Academic Press

Lovelli S, Perniola M, Ferrara A, Amato M, Tommaso TD (2010) Photosynthetic response to water stress of pigweed (Amaranthus retroflexus) in a Southern-Mediterranean area. Weed Sci 58:126-131

Masle J, Passioura JB (1987) The effect of soil strength on the growth of young wheat plants. Aust J Plant Physiol 14:643-656

Mayer DG, Butler DG (1993) Statistical validation. Ecol Model 68:21-32 
Moore JE, Franklin SB (2011) Understanding the relative roles of disturbance and species interactions in shaping Mississippi River island plant communities. Community Ecol 12:108-116

Moran PJ, Showler AT (2005) Plant responses to water deficit and shade stresses in pigweed and their influence on feeding and oviposition by the beet armyworm (Lepidoptera: Noctuidae). Environ Entomol 34:929-937

Nordby D, Hartzler B, Bradley K (2007) Biology and Management of Waterhemp. Purdue Extension. GWC-13. $3 \mathrm{p}$

Patterson DT (1995) Effects of environmental stress on weed/ crop interactions. Weed Sci 43:483-490

Roman ES, Murphy SD, Swanton CJ (2000) Simulation of Chenopodium album seedling emergence. Weed Sci 48:217-224

Ruiter HD, Meinen E (1998) Influence of water stress and surfactant on the efficacy, absorption, and translocation of glyphosate. Weed Sci 46:289-296

Sarangi D, Sandell LD, Knezevic SZ, Aulakh JS, Lindquist JL, Irmak S, Jhala AJ (2015) Confirmation and control of glyphosate-resistant common waterhemp (Amaranthus rudis) in Nebraska. Weed Technol 29:82-92

Shoup DE, Al-Khatib K, Peterson DE (2003) Common waterhemp (Amaranthus rudis) resistance to protoporphyrinogen oxidase-inhibiting herbicides. Weed Sci 51:145-150

Spiess AN, Neumeyer N (2010) An evaluation of R2 as an inadequate measure for nonlinear models in pharmacological and biochemical research: a Monte Carlo approach. BMC Pharmacol 10:6

Steadman KJ, Ellery AJ, Chapman R, Moore A, Turner NC (2004) Maturation temperature and rainfall influence seed dormancy characteristics of annual ryegrass (Lolium rigidum). Aust J Agric Res 55:1047-1057

Steckel LE, Sprague CL (2004) Common waterhemp (Amaranthus rudis) interference in corn. Weed Sci 52:359-364

Steckel LE, Sprague CL, Hager AG, Simmons FW, Bollero GA (2003) Effects of shading on common waterhemp (Amaranthus rudis) growth and development. Weed Sci 51:898-903
Steckel LE, Sprague CL, Stoller EW, Wax LM, Simmons FW (2007) Tillage, cropping system, and soil depth effects on common waterhemp (Amaranthus rudis) seed-bank persistence. Weed Sci 55:235-239

Waselkov KE, Olsen KM (2014) Population genetics and origin of the native North American agricultural weed waterhemp (Amaranthus tuberculatus; Amaranthaceae). Am J Bot 101: 1726-1736

Webster TM, Grey TL (2008) Growth and reproduction of Benghal dayflower (Commelina benghalensis) in response to drought stress. Weed Sci 56:561-566

Werle R, Bernards ML, Arkebauer TJ, Lindquist JL (2014a) Environmental triggers of winter annual weed emergence in the midwestern United States. Weed Sci 62:83-96

Werle R, Sandell LD, Buhler DD, Hartzler RG, Lindquist JL (2014b) Predicting emergence of 23 summer annual weed species. Weed Sci 62:267-279

Werle R, Schmidt JJ, Laborde J, Tran A, Creech CF, Lindquist JL (2014c) Shattercane $\times$ ALS-tolerant sorghum F1 hybrid and shattercane interference in ALS-tolerant sorghum. J Agric Sci 6: 159-165

Wu D, Qu JJ, Hao X, Xiong J (2013) The 2012 agricultural drought assessment in Nebraska using MODIS satellite data. Pages 170-175 in Proceedings of 2nd International Conference on Agro-Geoinformatics. Fairfax, VA: Center for Spatial Information Science and Systems

Young IM, Montagu K, Conroy J, Bengough AG (1997) Mechanical impedance of root growth directly reduces leaf elongation rates of cereals. New Phytol 135:613-619

Received March 27, 2015, and approved June 19, 2015.

Associate Editor for this paper: Martin M. Williams, II, USDA-ARS. 